\title{
1 Complex multi-trait responses to multivariate environmental cues in a
}

\section{2 seasonal butterfly}

3 Pragya Singh ${ }^{1,2,3 \dagger}$, Erik van Bergen ${ }^{3,4}$, Oskar Brattström ${ }^{3,5}$, Dave Osbaldeston ${ }^{3}$, Paul M.

$4 \quad$ Brakefield $^{3}$ and Vicencio Oostra ${ }^{3,4}$

$5{ }^{1}$ Evolutionary Biology, Zoological Institute, University of Basel, Basel 4055, Switzerland

$6 \quad{ }^{2}$ Indian Institute of Science Education and Research, Kolkata

$7 \quad{ }^{3}$ Department of Zoology, University Museum of Zoology Cambridge, University of

8 Cambridge, Cambridge, CB2 3EJ, United Kingdom

$9{ }^{4}$ Research Centre for Ecological Change, University of Helsinki, PO Box 65 (Viikinkaari 1),

10 FI-00014 University of Helsinki, Finland

$11{ }^{5}$ School of Life Sciences, University of Glasgow, Glasgow, G12 8QQ, United Kingdom

13 Corresponding Author:

14 University of Basel, Zoological Institute, Evolutionary Biology, Vesalgasse 1, 4051 Basel,

15 Switzerland

16 Email: pragya.singh42019@gmail.com

17 ORCiD: https://orcid.org/0000-0002-7411-3206

18

19 Acknowledgements: We would like to thank Andrew Balmer for help with the plant

20 measurements, and the Radiating Butterflies Group for helpful discussions. This study was

21 supported by funding for summer studentship from Trinity College, Cambridge, an INSPIRE 
22 scholarship travel fund to PS, and an Advanced Grant from the European Research Council

23 (EMARES - 250325) to PMB.

24 Author contributions: All authors designed the experiments. PS and VO performed the

25 experiments, statistically analysed the data and wrote the manuscript, with input from EvB,

26 OB and PMB. All authors have read and approved the final version.

27

28 Data accessibility: All data in this manuscript will be deposited online on Zenodo (xx). 
Developmental plasticity in a seasonal environment allows an organism to optimally match its life-history traits with the fluctuating conditions. This critically relies on abiotic and biotic

32 factors, such as temperature or food quality, that act as environmental cues and predict seasonal transitions. In most seasonal environments, multiple factors vary together, making it crucial to understand their combined effects on an organism's phenotype. Here, we study plasticity in a multivariate environment in the butterfly Bicyclus anynana that exhibits two distinct seasonal phenotypes. Temperature is an important cue mediating plasticity in this species, but other environmental cues such as larval host plant quality could also be informative since plant quality deteriorates during the transition from wet to dry season in the field. We examine how temperature and host plant quality interact to affect life-history traits. Using a full-factorial design, we expose cohorts of larvae to either poor (old plants) or high (young plants) quality plants at different temperatures. Our results show that plant quality had

42 a temperature and sex-dependent effect on life-history traits. At lower and intermediate temperatures, it decreased body mass and prolonged development time, indicating that poor plant quality acted as a stressor. However, metabolic rates in adults were not affected, indicating that individuals could, at least in part, compensate for stressful juvenile conditions. In contrast, at higher temperatures poor plant quality induced a partial dry-season phenotype,

47 indicating that it may have acted as an environmental cue. Moreover, poor plant quality, particularly in males, also decreased the correlation between life history traits, signifying disrupted phenotypic integration. Our study reveals complex interactive effects of two environmental variables on seasonal plasticity, reflecting differences in their reliability as

51 seasonal cues. This highlights the importance of studying the combined effects of multiple

52 environmental factors to better understand the regulation of phenotypic plasticity in wild. 


\section{Keywords}

54 developmental plasticity, food stress, plant quality, seasonal polyphenism, Bicyclus anynana,

\section{5 reaction norm}

56 


\section{Introduction}

58 Environmental seasonality is frequent in nature and can lead to the evolution of phenotypic

59 plasticity (Tauber et al. 1986, Gotthard and Nylin 1995, Lafuente and Beldade 2019).

60 Plasticity can help to ensure that the phenotype expressed by an organism matches the

61 requirements of the organism's environment, and often involves trade-offs between life-

62 history traits such as reproduction and lifespan, or growth rate and body size (Nylin 1992,

63 Flatt and Heyland 2011, Torres-Dowdall et al. 2012). A particular case of phenotypic

64 plasticity is developmental plasticity, where phenotypic changes are induced by the

65 environment experienced during development (Beldade et al. 2011). Developmental plasticity

66 can be adaptive in seasonal environments as it can allow organisms to adjust their life history

67 strategy for future conditions well before the new season starts, using predictive

68 environmental cues present during the course of development. Environmental cues can range

69 from abiotic factors, like temperature and day-length, to biotic factors, such as food quality

70 and predator presence. A special type of developmental plasticity is the Predictive Adaptive

71 Response (PAR), in which an organism adjusts its phenotype to maximize fitness in future

72 environmental conditions, even though the phenotype might not be immediately advantageous

73 in the current environment. In fact, the phenotype could be maladaptive if the expected

74 environmental change does not occur (Ghalambor et al. 2007, Monaghan 2008, Saastamoinen 75 et al. 2010).

77 In a seasonal environment multiple environmental factors often vary together (Jackson et al.

78 2009, Chevin and Lande 2015). For example, low precipitation is usually accompanied by a

79 decline in quantity or quality of resources. This leads to key open questions about i) whether

80 organisms sense the environment through one or multiple cues, ii) whether these cues interact 
81 (E x E) or act as independent predictors, and iii) whether they are processed in similar

82 manners leading to similar phenotypic responses. One hypothesis would be that the factors act

83 together as cues to predict future environmental conditions and potentially lead to an additive

84 adaptive response. Alternatively, one factor could act as a cue, while the other environmental

85 factor may not be perceived or processed at all, or could even be a stressor that disrupts the

86 phenotype or phenotypic integration. Theoretical work has shown that when the relationship

87 between an environmental cue and future conditions is weak, plasticity may not evolve in response to the environmental predictor (Tufto 2000, Leimar et al. 2006, Reed et al. 2010). Moreover, in a case where multiple cues are used by an organism to respond to the environment, the responses to a single cue might be nonintuitive and misleading (Chevin and Lande 2015). While many earlier studies on plasticity have manipulated one environmental cue at a time, it is more likely that multiple environmental cues vary simultaneously in natural seasonal environments, making it important to study plasticity in a multivariate environment.

To investigate the effect of multivariate environment on developmental plasticity, we use the seasonally polyphenic butterfly Bicyclus anynana. This species exhibits two alternative

97 seasonal forms (dry and wet) which correspond to a cool and a warm season, respectively. In addition to differences in morphology (Brakefield and Reitsma 1991), physiology (Oostra et al. 2011), and behaviour (van Bergen and Beldade 2019), the forms also differ markedly in their life-history traits (e.g. Oostra et al. 2011). Previous studies have shown that the

101 temperature experienced during the (late) larval stage is a crucial cue for plasticity in this 102 species (Brakefield and Reitsma 1991, Brakefield et al. 2007, 2009). Interestingly, variation in temperature alone does not produce the full extent of plasticity in life-history traits as 104 observed in the wild (Roskam and Brakefield 1999), suggesting that other predictive 105 environmental factors may act in conjunction with temperature (Brakefield 1987, Brakefield 
and Reitsma 1991). Here, we hypothesise that larval host plant quality could be an important environmental cue, in addition to temperature, for developing individuals in the field. During the transition from wet to dry season in the field, the plants on which the larvae feed tend to be old and of poor quality (Brakefield and Reitsma 1991, Kooi et al. 1996). Moreover, earlier work in B. anynana has shown that this species, under conditions of food limitation, is able to produce a PAR phenotype (i.e. better adapted to cope with stressful conditions as an adult) (Saastamoinen et al. 2010, van den Heuvel et al. 2013).

In our study, we test how larval host plant quality-in conjunction with temperature-affects a suite of life history traits. In particular, using old host plants that mimic the deteriorating conditions in dry season, we feed cohorts of individuals for a part of larval development on old (poor quality) plants. Data collected from these individuals is compared to those of cohorts that had been reared on young (high quality) plants throughout development. These treatments enable an examination of whether larval host plant quality affects the phenotype. Furthermore, we test the effect of host plant quality at three different temperatures that correspond to wet, intermediate and dry season temperatures in the field. This design allows testing of how larval host plant quality and temperature interact to affect larval and pupal development time, pupal and adult mass, resting metabolic rate (RMR) and the respiratory quotient of adults. Earlier studies using this species examined RMR by measuring $\mathrm{CO}_{2}$ respiration rate (Brakefield et al. 2007, Pijpe et al. 2007), and have showed that it varies in response to temperature. However, as of yet, no study has examined the $\mathrm{O}_{2}$ consumption or respiratory quotient in B. anynana. Examining the respiratory quotient allows us to evaluate whether adults differ in their macronutrient metabolism in response to environmental conditions (i.e. whether they burn different fuels, in particular fat, protein and carbohydrates). Finally, we tested whether the host plant quality affects the organismal integration of 
131 phenotypic traits by examining the correlation between life-history traits. The response of

132 different phenotypic traits to environmental cues might be correlated (van Bergen et al. 2017),

133 e.g. due to similar underlying physiological processes, but under stress we might expect the

134 synchronised response of the traits to become uncoupled and phenotypic integration to

135 decrease.

136 


\section{Materials and Methods}

\section{Study organism}

139 Bicyclus anynana is a Nymphalid butterfly from East Africa and is a model organism for

140 studying seasonal and developmental plasticity (Brakefield et al. 2009). It is found in

141 savannah grasslands and open woodlands (both seasonal ecosystems) and has probably

142 evolved developmental plasticity as an adaptation to seasonality in the environment. The two

143 seasons that $B$. anynana experiences are the warm wet season and the cool dry season, and the

144 species expresses alternative morphs in these two alternative seasons. The wet season

145 butterflies experience high temperatures and precipitation during development, and adults

146 have larger, more conspicuous eyespots on their ventral wing surfaces, shorter larval and

147 pupal developmental periods, lower pupal and adult mass, shorter lifespan and reproduce

148 relatively early (Brakefield et al. 2009, Oostra et al. 2011). In contrast, the dry season larvae

149 that develop during the late wet season experience relatively cooler temperatures and lower

150 precipitation which is associated with the transition from wet to dry season (Windig et al.

151 1994, van Bergen et al. 2016). Moreover, dry season adults accumulate higher mass and fat

152 reserves during development; have small or absent eyespots, a higher metabolic rate, delayed

153 reproduction until the following wet season, and a longer lifespan (Brakefield and Reitsma

154 1991, Pijpe et al. 2007, Oostra et al. 2011, Halali et al. 2019). The seasons, along with

155 differing in temperature and precipitation, also differ drastically in the availability of

156 resources, with the cool dry season having a reduced host plant quantity and quality (Roskam

157 and Brakefield 1999, van Bergen et al. 2016). The adults of this butterfly species feed on

158 rotting and fermenting fruit and the larvae utilize grasses. 


\section{Experimental design and rearing}

161

162

163

164

An outbred laboratory stock of the butterfly B. anynana was used for the experiment. The stock was established in 1988 from numerous gravid females collected in Malawi. Adults are fed on banana, and the larvae are reared on maize (Zea mays) (Brakefield et al. 2009).

We used a full-factorial design to investigate the effects of larval host plant quality, pre-adult (i.e. larval and pupal) temperature, and their interaction on a suite of life-history traits. Three temperature treatments $\left(19,23\right.$ and $27^{\circ} \mathrm{C}$, representing dry, intermediate, and wet season conditions, respectively) and two plant quality treatments (old maize, young maize) were used. Eggs were collected daily from the stock population. One day after hatching, larvae were randomly allocated to cages $(35 \mathrm{~cm} \times 44 \mathrm{~cm} \times 65 \mathrm{~cm})$ with young maize plants set up in climate rooms at $19^{\circ} \mathrm{C}$ and $27^{\circ} \mathrm{C}$, and in smaller climate-cabinets (Sanyo/Panasonic MLR$350 \mathrm{H}$ ) at $23^{\circ} \mathrm{C}$ (all at $75 \%$ relative humidity and a $12 \mathrm{~h}: 12 \mathrm{~h}$ day: night light cycle). Each cage had at least 140 larvae (950 larvae in total, Table 1). One day after they moulted to the 4th instar, larvae were switched to the host plant treatment: old maize or fresh young plants. The larvae were only exposed to the host plant treatment during the final two larval instars, which is the period when most growth occurs and the effect of food quality should be most prominent. In addition, this period is close to the pupal stage when the adult phenotype is differentiated. The resulting pupae were then individually placed in transparent pots, assigned an ID and kept at their temperature treatment, until they eclosed.

After randomly culling excess pupae raised at $19^{\circ} \mathrm{C}$ and excluding 51 individuals due to missing information about one or multiple life-history traits, the final sample size across all treatments was 548 (see Table 1). 
185 Host plant quality treatments

186 All maize plants were grown from seed and reared in a climate-controlled greenhouse in

187 Madingley (United Kingdom), with regular watering to keep the soil moist at all times. Young 188 maize plants were 2-3 weeks old whereas old maize plants were at least 5-7 weeks old. Earlier 189 studies have shown that plant quality varies with age. For example, older plants typically have 190 tougher leaves (Choong 1996, Loney et al. 2006), lower nutritional values (Hikosaka et al. 191 1994) and different chemical/physical defences against herbivory (Barton and Koricheva 192 2010) than younger plants. These differences can have pronounced effects on herbivory (Price 193 et al. 1987, Loney et al. 2006), with the incidence of herbivorous invertebrates on old host 194 plants typically being lower than on young plants (Choong 1996, Fenner et al. 1999, Boege 195 and Marquis 2005). Thus, older host plants can be inferred to be of poor quality relative to 196 younger host plants. Moreover, host plant quality can also directly regulate phenotypic 197 plasticity in herbivorous insects (Lin et al. 2018).

In our experiment, we measured the maximum leaf width and height of each maize plant

200 before feeding it to the larvae. For old maize plants, plant height was $92.2 \pm 33.2$ (mean \pm sd)

$201 \mathrm{~cm}$ and maximum leaf-width was $4.2 \pm 0.6 \mathrm{~cm}$. For young maize plants, plant height was

$20269.6 \pm 4.5 \mathrm{~cm}$ and maximum leaf-width was $1.4 \pm 0.2 \mathrm{~cm}$. The larvae were reared on whole plants (multiple larvae per plant), and ad libitum feeding was ensured by providing new plants

204 whenever needed. When the old plants were too large to be completely accommodated inside 205 the cage, only a part of the (whole) plant was put inside, while ensuring that the larvae could 206 not escape from the cage. 


\section{Life-history traits}

209 For each individual, larval development time was recorded as the number of days between

210 hatching of the egg and pupation of the larvae, and pupal development time was recorded as

211 the number of days between pupation and eclosion of the butterfly. Pupae were weighed

212 approximately $24 \mathrm{~h}$ after pupation. Adults were weighed and resting metabolic rate (RMR)

213 measurements made one day after eclosion. For the RMR measurements, individual

214 butterflies were measured in the dark-at their rearing temperature-in small cylindrical glass

215 containers ( $4 \mathrm{~cm}$ in diameter $\times 9 \mathrm{~cm}$ in height). Each RMR cycle consisted of three runs of 20

216 minutes during which RMR was measured as the individual rate of $\mathrm{CO}_{2}$ and $\mathrm{O}_{2}$ respiration

217 (millilitre per minute), using stop-flow respirometry (Pijpe et al. 2007). $\mathrm{CO}_{2}$ and $\mathrm{O}_{2}$

218 production were measured using a LI-7000 $\mathrm{CO}_{2}$ gas analyser (Li-Cor) and an Oxzilla FC-2

219 Differential Oxygen Analyzer (Sable Systems), respectively, and acquired data were handled

220 in Expedata (Sable Systems). The $\mathrm{CO}_{2}$ and $\mathrm{O}_{2}$ respiration rates were scaled to mass by

221 dividing respiration rate by adult mass. Measurements were taken at the same time of the day

222 for all individuals, and the data from the second and third runs were averaged. The first run

223 was excluded for each individual as this occurred during the butterfly's acclimation phase.

224 The respiratory quotient was calculated as the $\mathrm{CO}_{2}$ respiration rate divided by the $\mathrm{O}_{2}$

225 respiration rate (Richardson 1929).

\section{Statistical analyses}

228 We performed a Chi-square Goodness-of-Fit test to test if host plant quality had an effect on

229 the larval and pupal survivorship. We also performed a Chi-Square Test for Independence to

230 assess if the host plant quality had a sex-specific effect on survivorship for each temperature. 
231 In addition, for each dependent variable (larval development time, pupal development time,

232 pupal mass, adult mass, $\mathrm{CO}_{2}$ and $\mathrm{O}_{2}$ respiration rates (unscaled and scaled by mass), and

233 respiratory quotient), we constructed a three-way ANOVA with temperature, host plant

234 quality, sex, and all interactions, as independent fixed factors. We evaluated each model and

235 removed the least significant term from this model at 0.05 significance level $(\mathrm{p}<0.05)$ in a

236 step-wise fashion to obtain the minimal adequate model. Here we report the results of the

237 minimal adequate model for all the dependent variables (Supplementary S1). Prior to

238 statistical analyses, all traits, except pupal mass, were log-transformed when they did not

239 fulfil the assumptions of a parametric test. We did post-hoc comparisons using t-tests and

240 corrected for multiple testing with Bonferroni correction.

242 To assess whether host plant quality had an effect on phenotypic integration, we calculated

243 Pearson's correlation coefficients among the log-transformed life-history traits (all traits

244 except unscaled $\mathrm{CO}_{2}$ and unscaled $\mathrm{O}_{2}$ respiration rates) for individuals reared on both young

245 and old host plants, and for each sex (i.e. four correlation coefficients per pair of traits). We

246 tested whether poor host plant quality disrupted the seasonal morphs by comparing the

247 correlation coefficient of each life-history trait pair between old and young host plants. We

248 converted the correlation coefficient into a $z$-score using Fisher's $r$-to- $z$ transformation and

249 compared these $z$-scores using the sample size for each coefficient, using the following

250 formula (Cohen et al. 2003):

$$
z_{\text {observed }}=\frac{\left(z_{\text {young }}-z_{\text {old }}\right)}{\sqrt{\frac{1}{n_{\text {young }}-3}+\frac{1}{n_{\text {old }}-3}}}
$$

252 where $z_{y o u n g}$ and $z_{\text {old }}$ are correlation coefficients and $n_{y o u n g}$ and $n_{\text {old }}$ are the sample sizes for

253 individuals on young and old host plants, respectively. We assessed whether the difference 
254 between the correlation coefficients was statistically significant $(\mathrm{P} \leq 0.05)$ by checking if the

$255 \mathrm{Z}_{\text {observed }}$ was greater than the critical value of \pm 1.96 .

257 All the analyses were done in R version 3.1.0 (R Development Core Team 2016).

260 In general, temperature and sex had a significant effect on all traits except respiratory

261 quotient, as had been found in previous studies (Pijpe et al. 2007, de Jong et al. 2010, Oostra

262 et al. 2011, 2014, Mateus et al. 2014). The effect of host plant quality varied among traits,

263 typically with a temperature and/or sex dependent effect (Table 1, Supplementary S1).

\section{Limited effect of host plant quality on pre-adult survivorship}

266

272 Consistent with earlier studies (Pijpe et al. 2007, de Jong et al. 2010, Oostra et al. 2011,

273 Mateus et al. 2014), development time decreased with increase in temperature, and males had

274 a shorter larval but longer pupal development time than females (Supplementary S1). In

275 contrast to the treatments at both ends of the thermal gradient $\left(19^{\circ} \mathrm{C}\right.$ and $\left.27^{\circ} \mathrm{C}\right)$, host plant 
276 quality had a significant effect on larval and pupal development time at $23^{\circ} \mathrm{C}$ (Figure 1 ). At this intermediate temperature the larvae/pupae took a longer time to develop on old maize.

\section{Temperature-dependent effects of host plant quality on body mass}

Host plant quality led to a temperature-specific reduction in pupal mass, and to a temperature and sex-specific effect on adult mass (Supplementary S1, Figure 2). On old maize, both sexes had lower pupal mass at $19^{\circ} \mathrm{C}$ and $23^{\circ} \mathrm{C}$, while both sexes had higher pupal mass on old maize at $27^{\circ} \mathrm{C}$, though the latter was not statistically significant. Furthermore, pupal mass significantly decreased with increasing temperature, and was higher in females. Both sexes had lower adult mass on old maize at $19^{\circ} \mathrm{C}$, while only females had a lower adult mass on old maize at $23^{\circ} \mathrm{C}$. Similar to pupal mass, both sexes had higher adult mass on old maize at $27^{\circ} \mathrm{C}$, though this effect was only significant for females. Females had a higher adult mass compared to males for all three temperatures.

\section{No effect of host plant quality on mass-scaled respiration rates and respiratory quotient}

Similar to pupal mass, unscaled $\mathrm{CO}_{2}$ and $\mathrm{O}_{2}$ respiration rate were significantly affected by the interaction between temperature and host plant quality (Supplementary S1, Figure 3, 4).

Adults of both sexes had a higher unscaled $\mathrm{CO}_{2}$ respiration rate when reared on old compared to young maize at $27^{\circ} \mathrm{C}$ (Figure 3). In contrast, there was no significant effect of plant quality on unscaled $\mathrm{O}_{2}$ respiration rate at any temperature (Figure 4). Females had significantly higher unscaled $\mathrm{CO}_{2}$ and $\mathrm{O}_{2}$ respiration rates than males. Moreover, on both old and young plants, unscaled $\mathrm{CO}_{2}$ and $\mathrm{O}_{2}$ respiration rates were significantly lower at $19^{\circ} \mathrm{C}$ compared to the other temperatures, but did not differ significantly between $23^{\circ} \mathrm{C}$ and $27^{\circ} \mathrm{C}$. However, after scaling (correcting) for body mass, only temperature and sex had a significant effect on 
$300 \mathrm{CO}_{2}$ and $\mathrm{O}_{2}$ respiration rates (Supplementary S1, Figure 3, 4), indicating that the effect of

301 food stress on $\mathrm{CO}_{2}$ and $\mathrm{O}_{2}$ respiration was modulated by a difference in body mass. Similar to

302 earlier studies on $\mathrm{CO}_{2}$ respiration rates in this species (Brakefield et al. 2007, Pijpe et al.

303 2007), both the $\mathrm{CO}_{2}$ and $\mathrm{O}_{2}$ respiration rate increased with temperature (with all temperatures

304 being significantly different from each other), and males had higher respiration rates than

305 females. The respiratory quotient was not affected by sex, temperature, food stress, or any

306 interactions between these factors (Supplementary S1, Figure 5).

308 Poor host plant quality disrupts phenotypic integration

309 Host plant quality significantly changed the correlation matrix for life-history traits in both

310 sexes (Figure 6, for details see Supplementary S2). Males were more severely affected, with

31113 out of 21 correlation coefficients being significantly different between young and old host

312 plants, while for females only 7 out of 21 correlation coefficients were significantly affected.

313 Amongst the significant changes, for males, all 13 correlation coefficients decreased on old

314 host plants while for females 5 correlation coefficients decreased and 2 correlation

315 coefficients increased on old host plants. Thus, in general, poor host plant quality resulted in a

316 less integrated phenotype with a decrease in correlations among life-history traits, especially

317 for males.

\section{Discussion}

321 While several earlier studies have examined the effect of food stress on life-history traits in

322 different organisms, relatively few studies have analysed the role of food quality as a 
323 predictive cue for future conditions, especially in combination with other cues such as different physiological responses.

temperature (Wilson 1994, Rotem et al. 2003, Bauerfeind and Fischer 2005, Coley et al. 2006, Rosa and Saastamoinen 2017). Examining the effect of food quality in combination with other environmental cues is important, as most seasonal environments in nature are usually characterized by multiple environmental factors varying together. In our experiment, we examined the effect of host plant quality in conjunction with temperature, and found that host plant quality had a temperature- and sex-specific effect on life-history traits.

Earlier studies using B. anynana and food deprivation as nutritional stress, had shown that stressed individuals had a reduced body mass and prolonged developmental time (Bauerfeind and Fischer 2005, Saastamoinen et al. 2010, 2013). These results contrast our findings and the difference in effect is likely due to the different approaches used; in the earlier studies individuals were starved (food deprivation) while in our study individuals were fed ad libitum on old host plants. These older host plants are expected to be less palatable (i.e. tougher), have lower nutritional values and differ in their composition of secondary metabolites relative to younger plants. Compared to food deprivation, larvae developing on old host plants were likely able to acquire sufficient resources and thus, demonstrated a less dramatic change in the life-history traits studied. Moreover, food deprivation and old host plants may activate

343 In our study, the effect of host plant quality on different life-history traits was temperature344 dependent, indicating that the effect depended on the physiological state of the organism 345 (which can also depend on temperature experienced). If reduced host plant quality can be 346 perceived as an environmental cue indicative of harsh (future) environmental conditions, we 
347 would have expected development on old host plants to lead to a more dry-season phenotype

348 (e.g. an increase in body mass). Indeed, when exposed to the thermal conditions of the wet-

349 season $\left(27^{\circ} \mathrm{C}\right)$, poor host plant quality induced a partial dry-season phenotype with an

350 increase in adult mass (significant for females). In contrast to the pattern observed at high

351 temperatures, at temperatures that mimic the dry season $\left(19^{\circ} \mathrm{C}\right)$, poor host plant quality did

352 not act as a seasonal cue. Instead, the treatment resulted in lower body mass and longer

353 development times, indicating a stress response. The increase in adult mass in wet-season

354 form butterflies $\left(27^{\circ} \mathrm{C}\right)$ could potentially indicate an adaptive response (e.g. PAR-like) for

355 within-season fluctuations in food quality. Food quality can potentially vary independently of

356 temperature, making it an important cue under conditions when the thermal information may

357 be inconclusive (see below).

359 Interestingly, for several traits, including larval survivorship and development time, we

360 observed a significant effect of host plant quality only at $23^{\circ} \mathrm{C}$, which is the average

361 temperature during the transition from the wet $\left(27^{\circ} \mathrm{C}\right)$ to the dry $\left(19^{\circ} \mathrm{C}\right)$ season (Windig et al.

362 1994, van Bergen et al. 2016). One possible explanation for observing the above effects only

363 at $23^{\circ} \mathrm{C}$ could be that increased sensitivity for host plant quality could be adaptive at this

364 temperature. Larvae developing during the transition between the seasons, or during a cold

365 spell in the wet season, may require additional environmental information to induce the

366 expression of the appropriate phenotype (see above). Moreover, the prolonged development

367 time at $23^{\circ} \mathrm{C}$ is likely due to the old maize being of a poorer quality (e.g. tougher leaves

368 and/or more secondary metabolites), prolonging the period necessary to reach the critical

369 mass needed for undergoing hormonal changes and pupation (Coley et al. 2006). Remarkably,

370 despite the prolonged time to acquire resources, the individuals reared on old plants had a

371 lower pupal mass (both sexes) and adult mass (only significant for females). 
373 In addition, the effect of host plant quality on body mass was more evident compared to the

374 effect on development time and survivorship at all thermal environments. This may be related

375 to the fact that the larvae were only exposed to the poor host plant quality during the final two

376 larval instars. The latter represents the period when most growth occurs, but it is only a short

377 period of the total development time, potentially resulting in more pronounced effects on

378 body mass compared to development time.

380 We also examined for the first time the respiratory quotient, the ratio between $\mathrm{CO}_{2}$ and $\mathrm{O}_{2}$

381 respiration rate at rest. We found that it was not influenced by either temperature, sex, host

382 plant quality, or their interactions. The respiratory quotient reflects which macronutrients are

383 metabolized for energy, with values of $0.7,0.8$ or 1.0 indicating fat, protein or carbohydrate

384 metabolism, respectively (Nunes et al. 1997). In our study, the respiratory quotient was

385 around 0.9 , which is intermediate between protein and carbohydrate metabolism, across all

386 temperatures. Thus, our results point towards adult macronutrient metabolism remaining

387 similar, irrespective of larval food quality. This is surprising, as earlier studies in both field

388 and laboratory showed that dry season form butterflies have a higher fat content (Brakefield

389 and Reitsma 1991, Pijpe et al. 2007, de Jong et al. 2010, Oostra et al. 2011). However, we

390 measured the metabolic rates of newly eclosed adults under benign conditions in the

391 laboratory where fat reserves are likely under-used compared to the wild, where adults often

392 face prolonged periods of desiccation and/or starvation.

394 The overall phenotypic integration of traits was affected by plant quality, with a decrease in

395 the correlation between life history traits on poor quality host plants, signifying disrupted 
396 phenotypic integration, particularly in males. Interestingly, a similar phenomenon of sexspecific effects of larval food stress on larval and adult performance has been found in a study using the Glanville fritillary butterfly, Melitaea cinxia (Rosa and Saastamoinen 2017). This could indicate that the underlying physiological processes that are responsible for phenotypic

400 integration, e.g. hormone signalling, may have a sex-specific component, and that stressors 401 affecting these processes result in a more extensive phenotypic disintegration in only one of 402 the sexes.

A possible explanation for the lack of a role of host plant quality as a cue of seasonal progression, at least in thermal conditions of the dry season, could be that temperature suffices as a cue, as our lab population of $B$. anynana originated from a location in Malawi where temperature is a highly reliable predictor of seasonal transitions (Oostra et al. 2018). Thus, the reliability of temperature may override the necessity for additional cues in this population. Hence, an interesting open question is whether food quality may be a more important cue in other parts of the species' range, where the relevance and reliability of

411 temperature as a cue is less (Roskam and Brakefield 1996, van Bergen et al. 2017). Future

412 studies could investigate the effect of host plant quality on life-history traits in populations or

413 species originating from regions where temperature is a relatively unreliable cue. In addition,

414 here we only exposed the larvae to old maize plants during the last two instars of

415 development, while the larvae of this species utilize a variety of grass species in the wild and 416 are likely to feed on poor quality host plants for longer periods (Brakefield et al. 2009, van

417 Bergen et al. 2016). The deteriorating effects of the dry season conditions on natural grasses

418 are likely to be host specific and longer exposure to poor quality host during development 419 may trigger more pronounced phenotypic effects. 
421 Taken together, plant quality affected life history traits in a temperature- and sex-specific

422

423

424

425

426

427

428

429

430

431

432

433

434

435

436

437

438

439

440

441

442

443

444

445

446

447

448

449

450

451

452

453

454

455

456

457

458

459

manner in our study, indicating that under certain environmental condition a single cue (e.g.

temperature) might suffice to shape an organisms' phenotype, while under other conditions

additional cues (like plant quality) might also become relevant in shaping the organism's

phenotype. Thus, it is important to study phenotypic plasticity in a multivariate environment

as multiple environmental factors can interact to produce different phenotypes, and are better

representative of conditions occurring in the wild.

\section{References}

Barton, K. E. and Koricheva, J. 2010. The ontogeny of plant defense and herbivory: characterizing general patterns using meta-analysis. - Am. Nat. 175: 481-493.

Bauerfeind, S. S. and Fischer, K. 2005. Effects of food stress and density in different life stages on reproduction in a butterfly. - Oikos 111: 514-524.

Beldade, P. et al. 2011. Evolution and molecular mechanisms of adaptive developmental plasticity. - Mol. Ecol. 20: 1347-1363.

Boege, K. and Marquis, R. J. 2005. Facing herbivory as you grow up: the ontogeny of resistance in plants. - Trends Ecol. Evol. 20: 441-448.

Brakefield, P. M. 1987. Tropical dry and wet season polyphenism in the butterfly Melanitis leda (Satyrinae): Phenotypic plasticity and climatic correlates. - Biol. J. Linn. Soc. 31: 175-191.

Brakefield, P. M. and Reitsma, N. 1991. Phenotypic plasticity, seasonal climate and the population biology of Bicyclus butterflies (Satyridae) in Malawi. - Ecol. Entomol. 16: 291-303.

Brakefield, P. M. et al. 2007. Developmental plasticity and acclimation both contribute to adaptive responses to alternating seasons of plenty and of stress in Bicyclus butterflies. J. Biosci. 32: 465-475.

Brakefield, P. M. et al. 2009. The African Butterfly Bicyclus anynana: A Model for Evolutionary Genetics and Evolutionary Developmental Biology. - Cold Spring Harb. Protoc. 2009: pdb.emo122-pdb.emo122.

Chevin, L. M. and Lande, R. 2015. Evolution of environmental cues for phenotypic plasticity. - Evolution (N. Y). 69: 2767-2775.

Choong, M. F. 1996. What makes a leaf tough and how this affects the pattern of castanopsis fissa leaf consumption by caterpillars. - Funct. Ecol. 10: 668.

Coley, P. D. et al. 2006. The effects of plant quality on caterpillar growth and defense against natural enemies. - Oikos 115: 219-228.

de Jong, M. et al. 2010. Geographic variation in thermal plasticity of life history and wing pattern in Bicyclus anynana. - Clim. Res. 43: 91-102.

Fenner, M. et al. 1999. Comparison of seedling and adult palatability in annual and perennial plants. - Funct. Ecol. 13: 546-551. 
Flatt, T. and Heyland, A. 2011. Mechanisms of Life History Evolution: The Genetics and Physiology of Life History Traits and Trade-Offs. - Genetics: 540.

Ghalambor, C. K. et al. 2007. Adaptive versus non-adaptive phenotypic plasticity and the potential for contemporary adaptation in new environments. - Funct. Ecol. 21: 394-407.

Gotthard, K. and Nylin, S. 1995. Adaptive plasticity and plasticity as an adaptation: a selective review of plasticity in animal morphology and life history. - Oikos 74: 3.

Halali, S. et al. 2019. To mate, or not to mate: the evolution of reproductive diapause facilitates insect radiation into African savannahs in the Late Miocene. - bioRxiv: 693812.

Hikosaka, K. et al. 1994. Effects of leaf age, nitrogen nutrition and photon flux density on the distribution of nitrogen among leaves of a vine (Ipomoea tricolor Cav.) grown horizontally to avoid mutual shading of leaves. - Oecologia 97: 451-457.

Jackson, S. T. et al. 2009. Ecology and the ratchet of events: climate variability, niche dimensions, and species distributions. - Proc. Natl. Acad. Sci. U. S. A. 106 Suppl: 19685-92.

Kooi, R. E. et al. 1996. Effects of food plant on phenotypic plasticity in the tropical butterfly Bicyclus anynana. - Entomol. Exp. Appl. 80: 149-151.

Lafuente, E. and Beldade, P. 2019. Genomics of Developmental Plasticity in Animals. Front. Genet. in press.

Leimar, O. et al. 2006. A new perspective on developmental plasticity and the principles of adaptive morph determination. - Am. Nat. 167: 367-376.

Lin, X. et al. 2018. Host quality induces phenotypic plasticity in a wing polyphenic insect. Proc. Natl. Acad. Sci. 115: 7563-7568.

Loney, P. E. et al. 2006. How does ontogeny in a Eucalyptus species affect patterns of herbivory by Brushtail Possums? - Funct. Ecol. 20: 982-988.

Mateus, A. R. A. et al. 2014. Adaptive developmental plasticity: Compartmentalized responses to environmental cues and to corresponding internal signals provide phenotypic flexibility. - BMC Biol. 12: 97.

Monaghan, P. 2008. Early growth conditions, phenotypic development and environmental change. - Philos. Trans. R. Soc. Lond. B. Biol. Sci. 363: 1635-45.

Nunes, L. et al. 1997. On the respiratory quotient (RQ) of termites (Insecta: Isoptera). - J. Insect Physiol. 43: 749-758.

Nylin, S. 1992. Seasonal plasticity in life history traits: growth and development in Polygonia c-album (Lepidoptera: Nymphalidae). - Biol. J. Linn. Soc. 47: 301-323.

Oostra, V. et al. 2011. Translating environmental gradients into discontinuous reaction norms via hormone signalling in a polyphenic butterfly. - Proc. R. Soc. B Biol. Sci. 278: 789797.

Oostra, V. et al. 2014. Ecdysteroid Hormones Link the Juvenile Environment to Alternative Adult Life Histories in a Seasonal Insect. - Am. Nat. 184: E79-E92.

Oostra, V. et al. 2018. Strong phenotypic plasticity limits potential for evolutionary responses to climate change. - Nat. Commun. 9: 1005.

Pijpe, J. et al. 2007. Phenotypic plasticity of starvation resistance in the butterfly Bicyclus anynana. - Evol. Ecol. 21: 589-600.

Price, P. W. et al. 1987. Plant age and attack by the bud galler, Euura mucronata. - Oecologia 73: 334-337.

R Development Core Team 2016. R: A Language and Environment for Statistical Computing. - R Found. Stat. Comput. Vienna Austria 0: \{ISBN\} 3-900051-07-0.

Reed, T. E. et al. 2010. Phenotypic plasticity and population viability: The importance of environmental predictability. - Proc. R. Soc. B Biol. Sci. 277: 3391-3400.

Richardson, H. B. 1929. The respiratory quotient. - Physiol. Rev. 9: 61-125. 
Rosa, E. and Saastamoinen, M. 2017. Sex-dependent effects of larval food stress on adult performance under semi-natural conditions: only a matter of size? - Oecologia 184: 633642.

Roskam, J. C. and Brakefield, P. M. 1996. A comparison of temperature-induced polyphenism in african bicylus butterflies from a seasonal savannah-rainforest ecotone. Evolution (N. Y). 50: 2360.

Roskam, J. C. and Brakefield, P. M. 1999. Seasonal polyphenism in Bicyclus (Lepidoptera: Satyridae) butterflies: Different climates need different cues. - Biol. J. Linn. Soc. 66: 345-356.

Rotem, K. et al. 2003. Parental effects in Pieris rapae in response to variation in food quality: adaptive plasticity across generations? - Ecol. Entomol. 28: 211-218.

Saastamoinen, M. et al. 2010. Predictive Adaptive Responses: Condition-Dependent Impact of Adult Nutrition and Flight in the Tropical Butterfly Bicyclus anynana. - Am. Nat. 176: 686-698.

Saastamoinen, M. et al. 2013. Quantitative genetic analysis of responses to larval food limitation in a polyphenic butterfly indicates environmentand trait-specific effects. Ecol. Evol. 3: 3565-3575.

Tauber, M. J. et al. 1986. Seasonal adaptations of insects. - Oxford University Press on Demand.

Torres-Dowdall, J. et al. 2012. Local adaptation and the evolution of phenotypic plasticity in trinidadian guppies ( Poecilia reticulata ). - Evolution (N. Y). 66: 3432-3443.

Tufto, J. 2000. The Evolution of Plasticity and Nonplastic Spatial and Temporal Adaptations in the Presence of Imperfect Environmental Cues. - Am. Nat. 156: 121-130.

van Bergen, E. and Beldade, P. 2019. Seasonal plasticity in anti-predatory strategies: Matching of color and color preference for effective crypsis. - Evol. Lett. 3: 313-320.

van Bergen, E. et al. 2016. The stable isotope ecology of mycalesine butterflies: implications for plant-insect co-evolution (KL Pum, Ed.). - Funct. Ecol. 30: 1936-1946.

van Bergen, E. et al. 2017. Conserved patterns of integrated developmental plasticity in a group of polyphenic tropical butterflies. - BMC Evol. Biol. 17: 59.

van den Heuvel, J. et al. 2013. The predictive adaptive response: modeling the life-history evolution of the butterfly Bicyclus anynana in seasonal environments. - Am. Nat. 181: E28-42.

Wilson, L. J. 1994. Plant-Quality Effect on Life-History Parameters of the Twospotted Spider Mite (Acari: Tetranychidae) on Cotton. - J. Econ. Entomol. 87: 1665-1673.

Windig, J. J. et al. 1994. Seasonal polyphenism in the wild: survey of wing patterns in five species of Bicyclus butterflies in Malawi. - Ecol. Entomol. 19: 285-298. 
550 Table 1. Larval and pupal survival (\% in brackets) for different temperatures. The larval survivorship was computed as the number of pupations

551 and is expressed as a percentage of the initial number of larvae reared. Pupal survivorship was the number of adults which eclosed and is

552 expressed as a percentage of the initial number of pupae.

$553 * *$ We discarded excess pupae at $19^{\circ} \mathrm{C}$ and only kept 130 pupae.

\begin{tabular}{|c|c|c|c|c|c|c|c|c|c|c|c|c|c|c|c|}
\hline \multirow{2}{*}{ 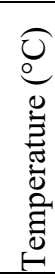 } & \multirow[b]{2}{*}{$\stackrel{\mathscr{N}}{\stackrel{\tilde{N}}{\Sigma}}$} & \multirow{2}{*}{ 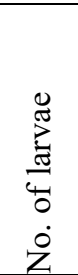 } & \multirow{2}{*}{ 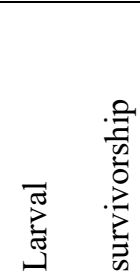 } & \multicolumn{3}{|c|}{$\begin{array}{l}\text { Chi-square test analysis of } \\
\text { larval survivorship }\end{array}$} & \multirow{2}{*}{ 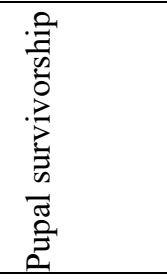 } & \multicolumn{3}{|c|}{$\begin{array}{l}\text { Chi-square test analysis of } \\
\text { pupal survivorship }\end{array}$} & \multirow{2}{*}{ 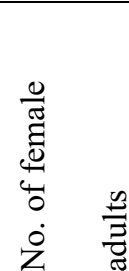 } & \multirow{2}{*}{ 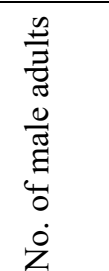 } & \multicolumn{3}{|c|}{$\begin{array}{l}\text { Chi-square test analysis of } \\
\text { survivorship of sexes }\end{array}$} \\
\hline & & & & $x$ & $\frac{4}{2}$ & 2 & & $x$ & $\frac{4}{2}$ & 2 & & & $x$ & 4 & 2 \\
\hline \multirow[t]{2}{*}{19} & old & 140 & $\begin{array}{l}98 \\
(70 \%)\end{array}$ & 0.2 & 1 & 0.66 & $91(93 \%)$ & 0.18 & 1 & 0.67 & $\begin{array}{l}46 \\
(100 \%)\end{array}$ & $\begin{array}{l}45 \\
(98 \%)\end{array}$ & 0.07 & 1 & 0.79 \\
\hline & young & 250 & $\begin{array}{l}185 \\
(74 \%)\end{array}$ & & & & $\begin{array}{l}128(98 \%) \\
* *\end{array}$ & & & & 67() & 61 & & & \\
\hline \multirow[t]{2}{*}{23} & old & 140 & $\begin{array}{l}102 \\
(73 \%)\end{array}$ & 4.34 & 1 & 0.04 & $95(93 \%)$ & 0.51 & 1 & 0.48 & 49 & 46 & 0.08 & 1 & 0.77 \\
\hline & young & 140 & $\begin{array}{l}134 \\
(96 \%)\end{array}$ & & & & $113(84 \%)$ & & & & 56 & 57 & & & \\
\hline
\end{tabular}




\begin{tabular}{|c|c|c|c|c|c|c|c|c|c|c|c|c|c|c|c|}
\hline 27 & old & 140 & $\begin{array}{l}91 \\
(65 \%)\end{array}$ & 2.17 & 1 & 0.14 & $74(81 \%)$ & 0.23 & 1 & 0.63 & 42 & 32 & 0.21 & 1 & 0.65 \\
\hline & young & 140 & $\begin{array}{l}112 \\
(80 \%)\end{array}$ & & & & $98(87 \%)$ & & & & 59 & 39 & & & \\
\hline
\end{tabular}

554

555

556

557 


\section{Figures}

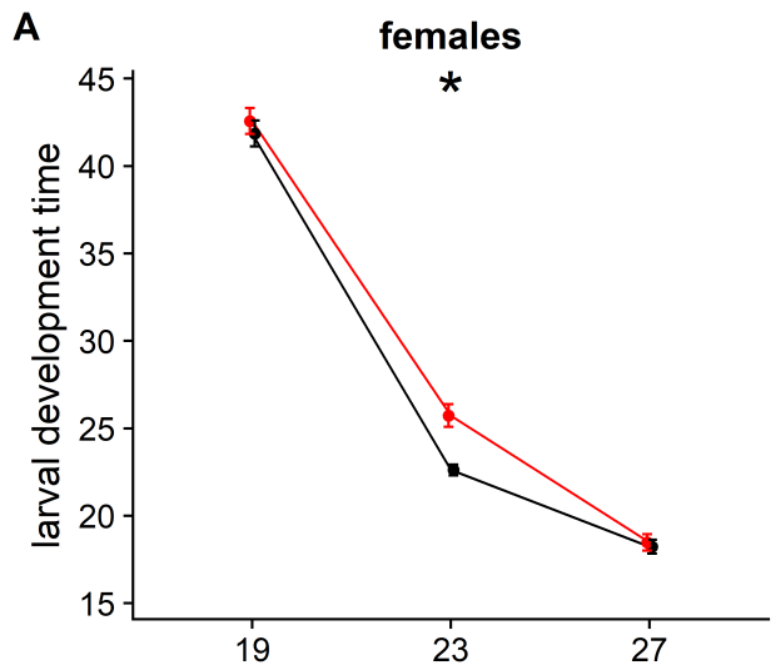

B
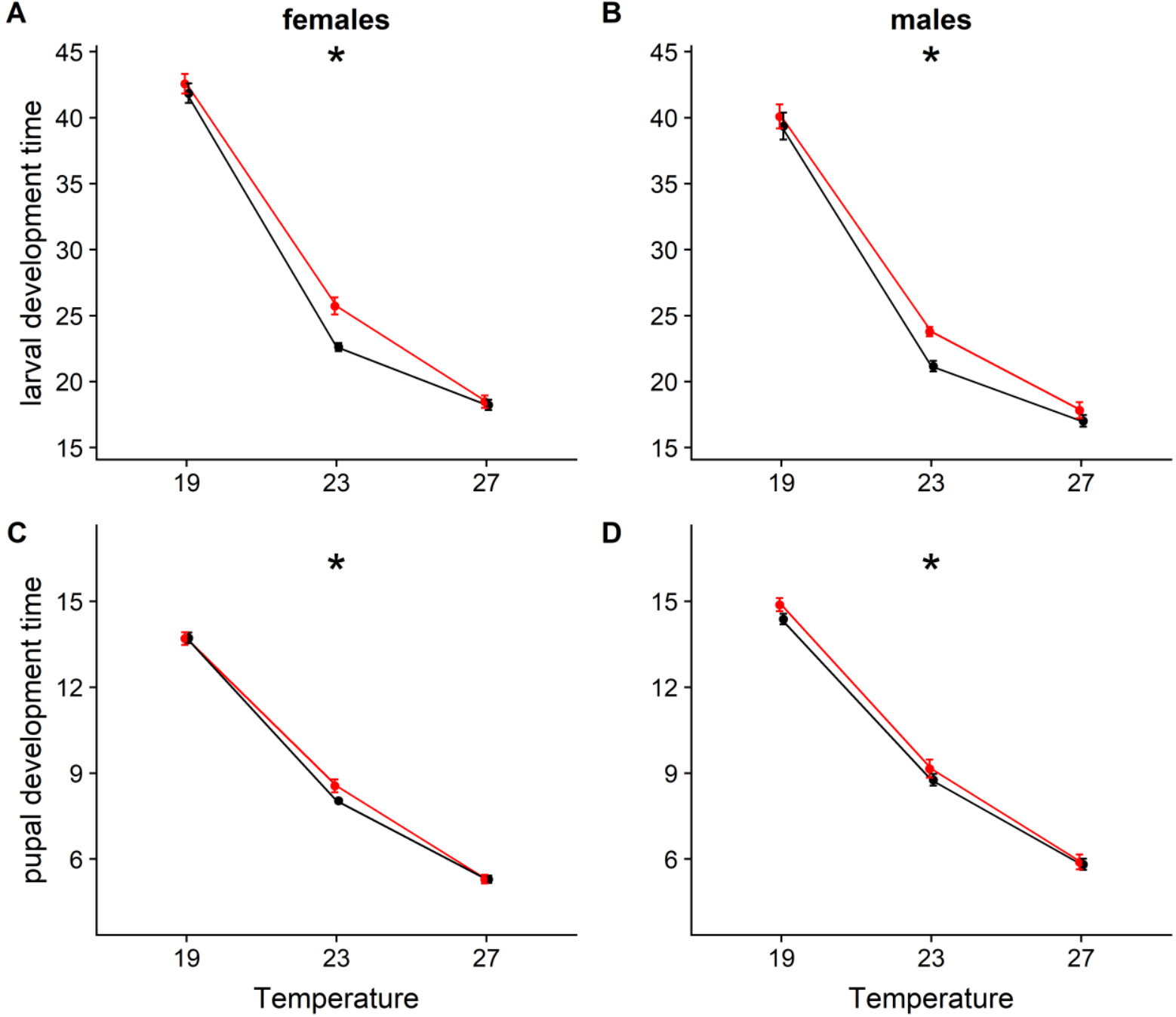

560 Figure 1. Slower development due to poor host plant quality at certain temperatures: Effect of

561 host plant quality and temperature on larval development time (top row) and pupal

562 development time (bottom row) in each sex. Plots show means and 95\% confidence intervals

563 of data. Statistically significant effect of host plant quality on development time is indicated

564 for each temperature with *, indicating $\mathrm{P} \leq 0.05$. Red lines represent old host plants and black 565 lines represents young host plants. 
A
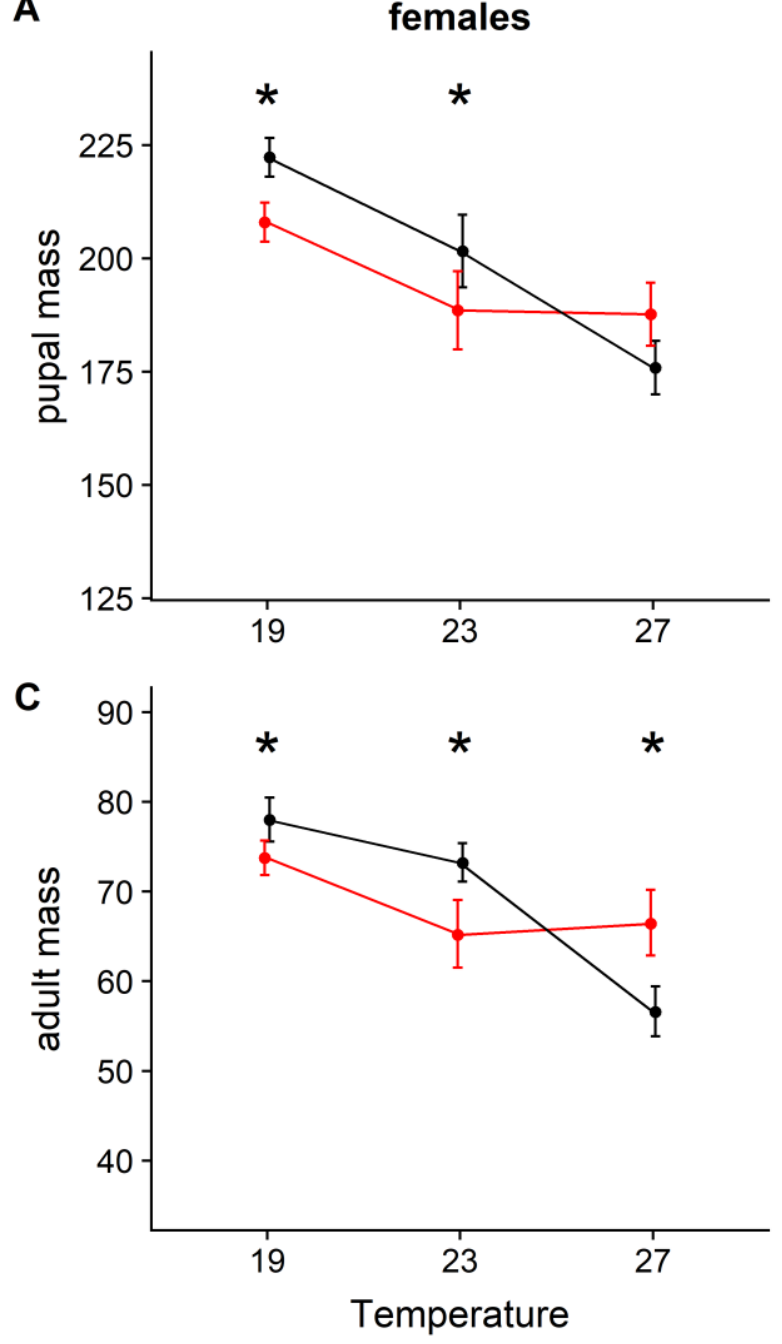

B

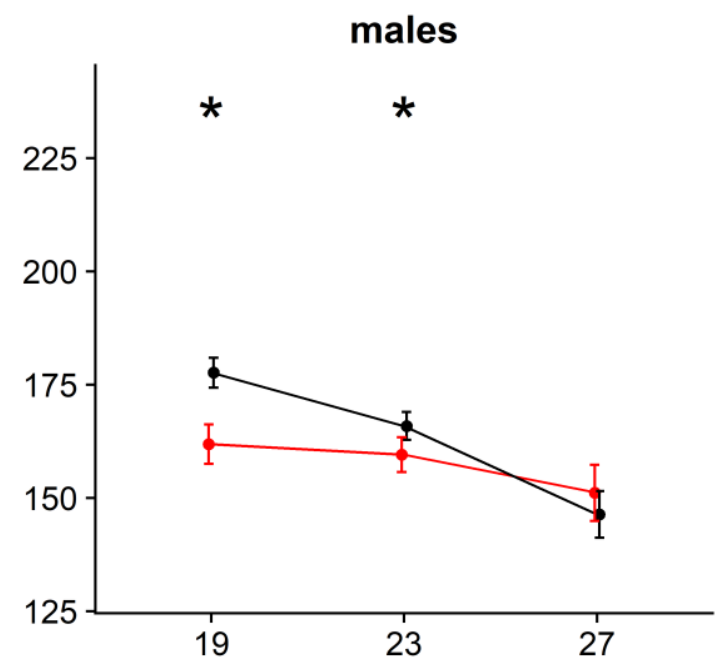

D

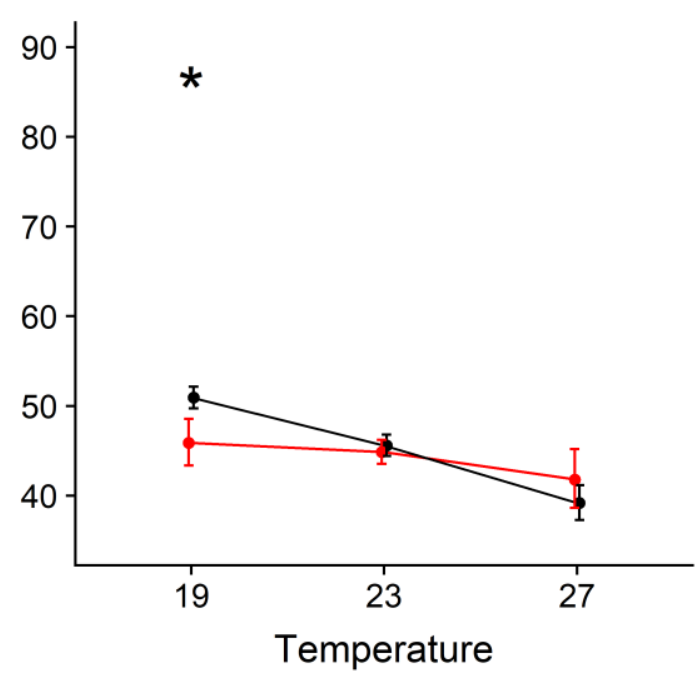

567 Figure 2. Temperature and sex-dependent effects of host plant quality on body mass: Effect of

568 host plant quality and temperature on pupal mass (top row) and adult mass (bottom row) in

569 each sex. Plots show means and 95\% confidence intervals of data. Statistically significant

570 effect of host plant quality on development time is indicated for each temperature with *,

571 indicating $\mathrm{P} \leq 0.05$. Red lines represent old host plants and black lines represents young host

572 plants. 
A
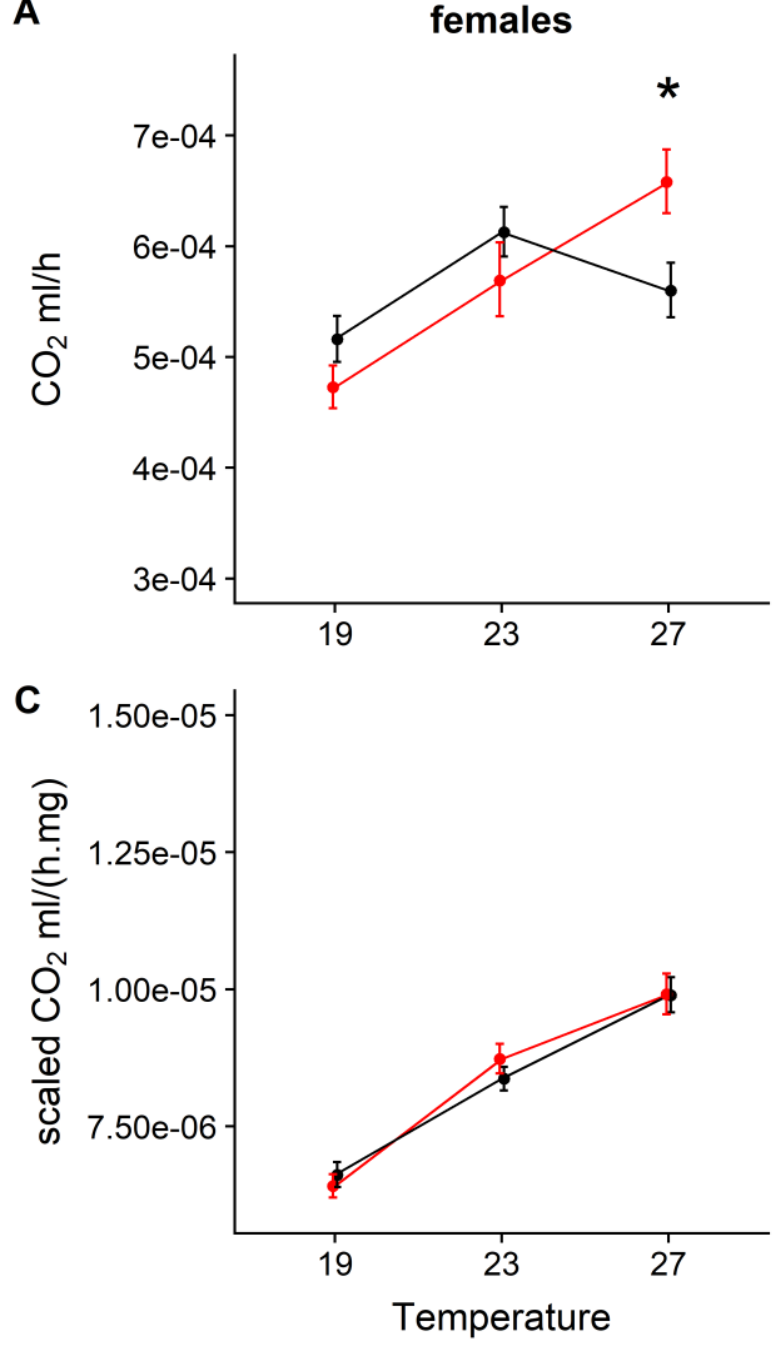

B

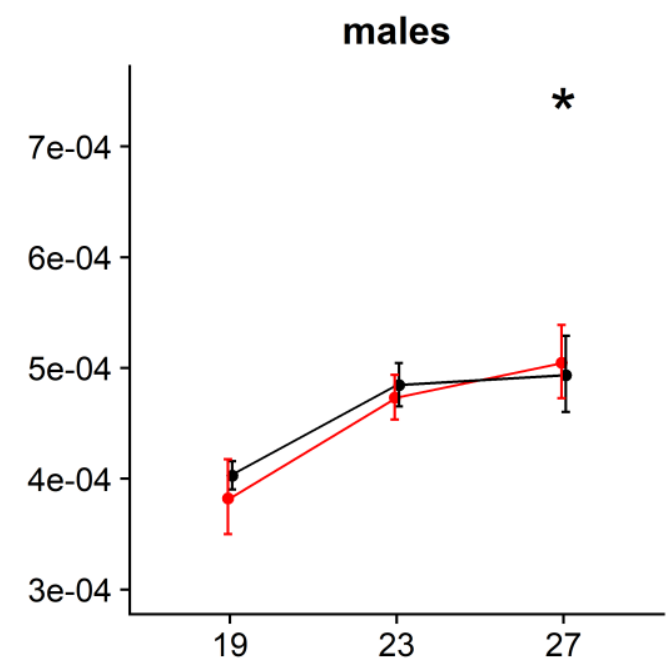

D

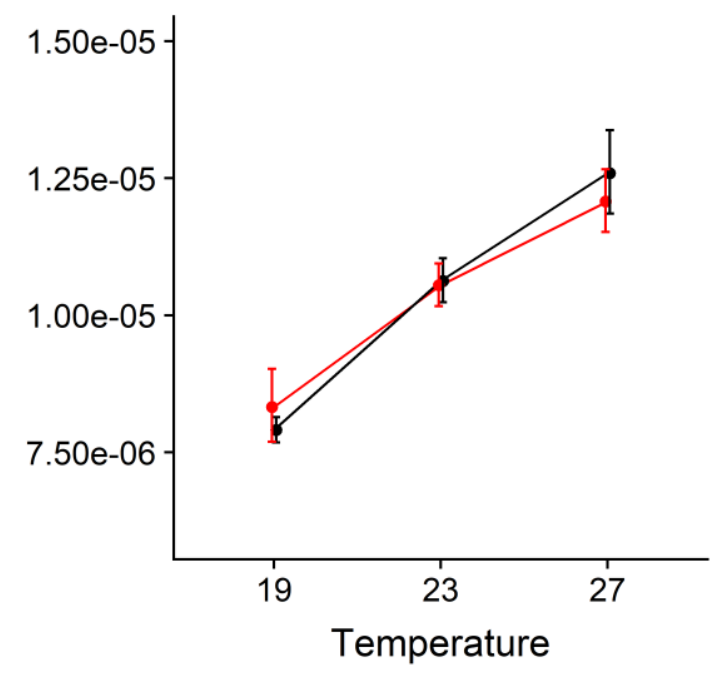

576 Figure 3. Limited effect of host plant quality on unscaled and scaled $\mathrm{CO}_{2}$ respiration rates

577 (production per hour): Effect of host plant quality and temperature on unscaled $\mathrm{CO}_{2}$

578 respiration rate (top row) and $\mathrm{CO}_{2}$ respiration rate scaled by mass (bottom row) in each sex.

579 Plots show means and 95\% confidence intervals of data. Statistically significant effect of host

580 plant quality on development time is indicated for each temperature with *, indicating $\mathrm{P} \leq 0.05$.

581 Red lines represent old host plants and black lines represents young host plants. 
A
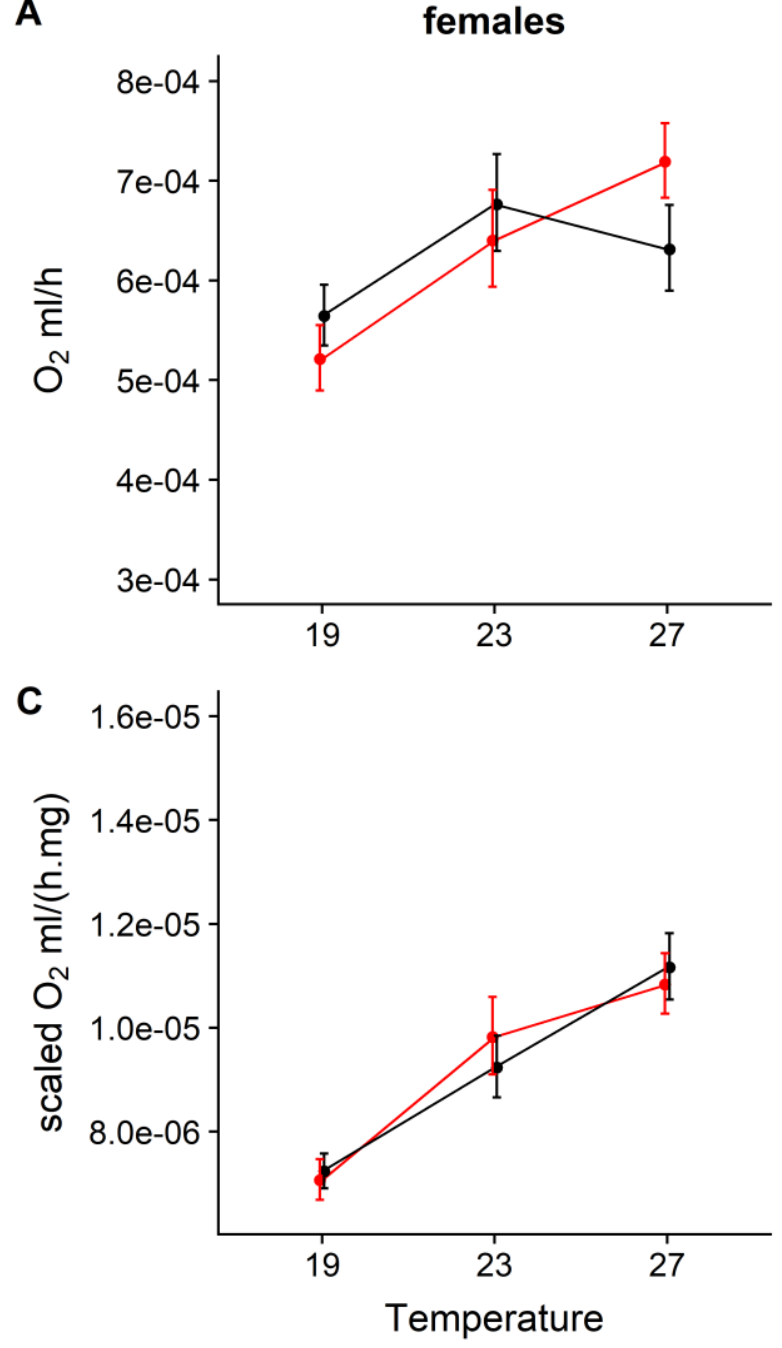

B

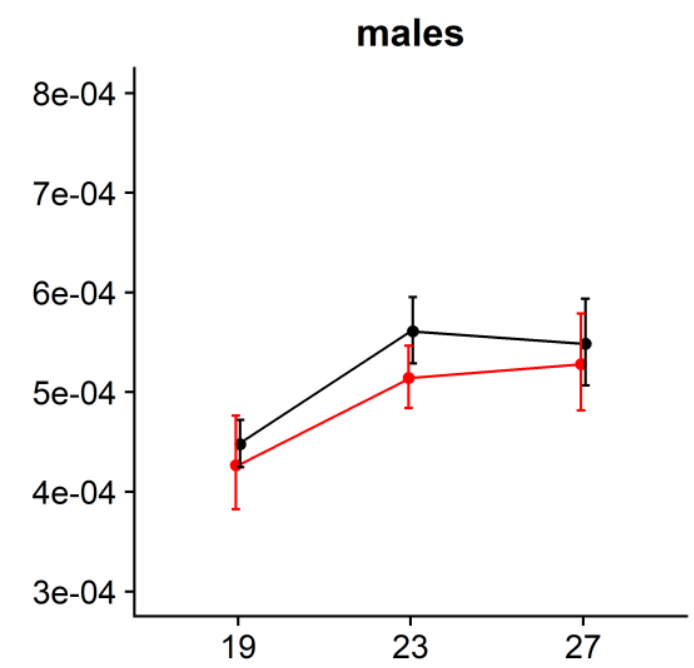

D

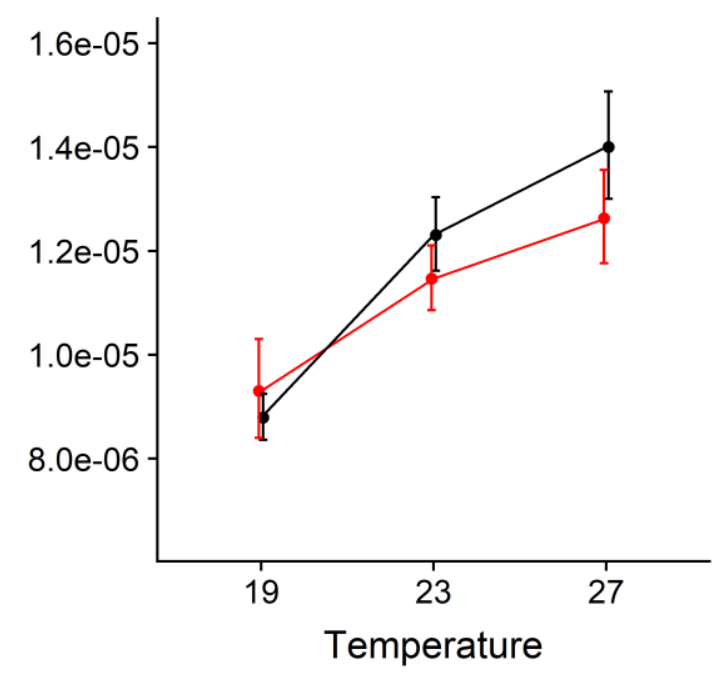

584 Figure 4. No effect of host plant quality on unscaled and scaled $\mathrm{O}_{2}$ respiration rates

585 (production per hour): Effect of host plant quality and temperature on unscaled $\mathrm{O}_{2}$ respiration

586 rate (top row) and $\mathrm{O}_{2}$ respiration rate scaled by mass (bottom row) in each sex. Plots show

587 means and 95\% confidence intervals of data. Red lines represent old host plants and black

588 lines represents young host plants. 
A

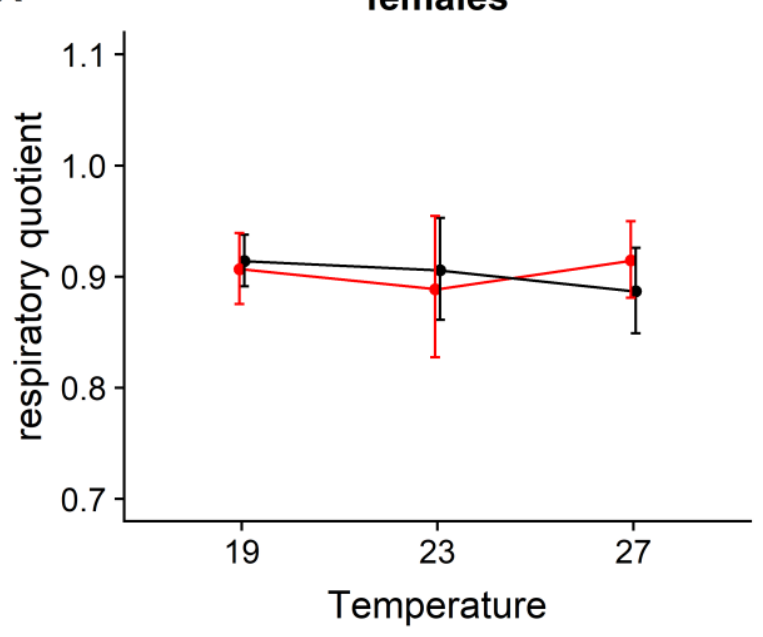

B

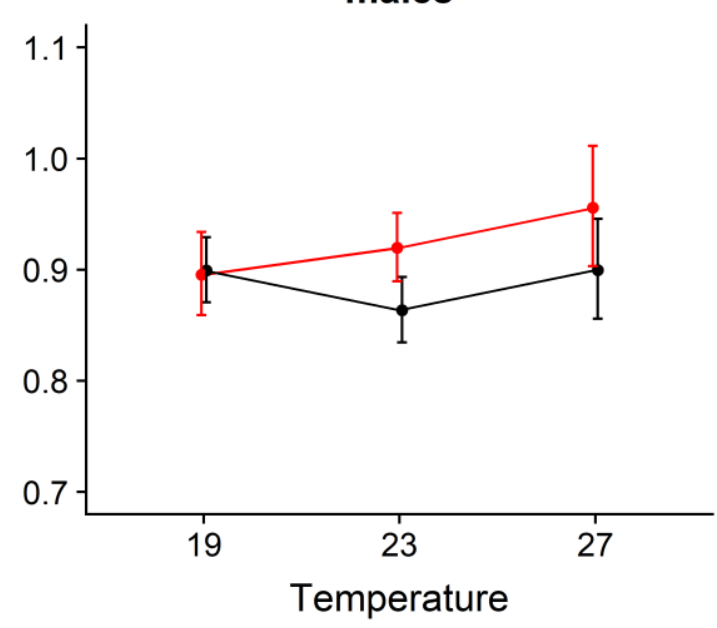

591 Figure 5. No effect of temperature and host plant quality on respiratory quotient in each sex.

592 Plots show means and $95 \%$ confidence intervals of data. Red lines represent old host plants

593 and black lines represents young host plants. 
A

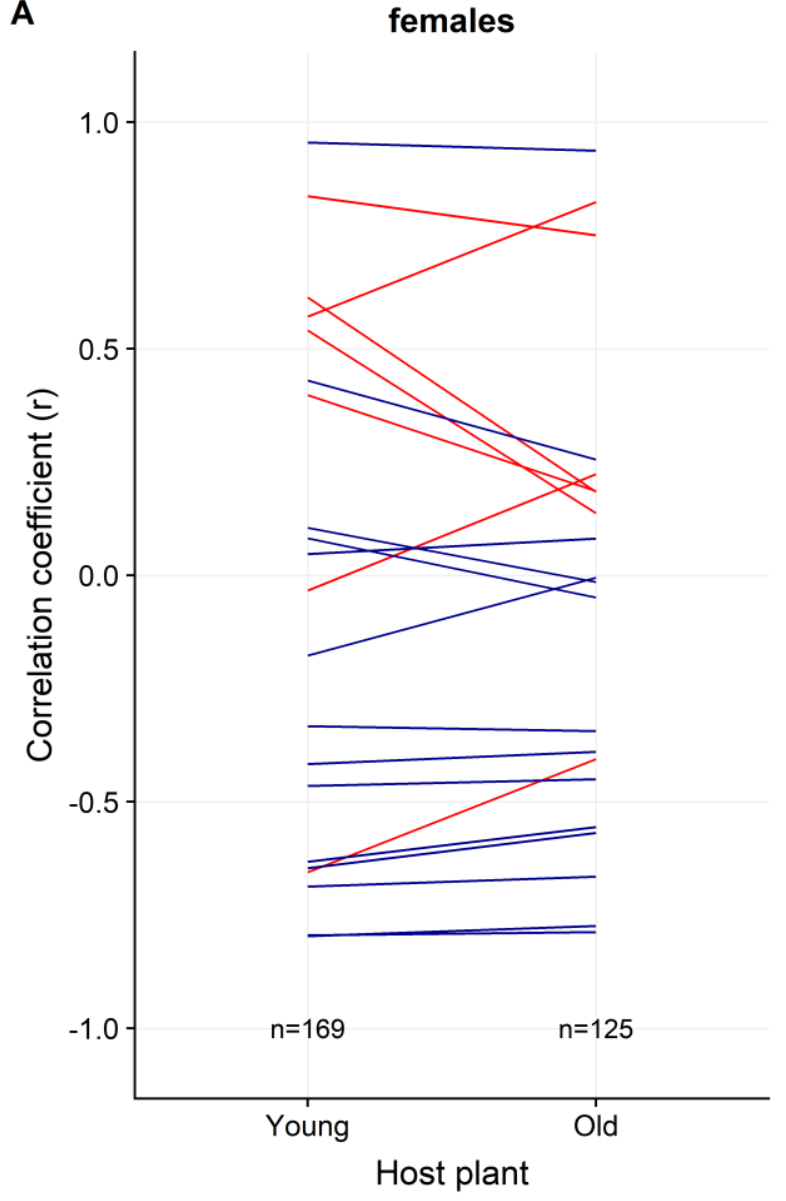

B

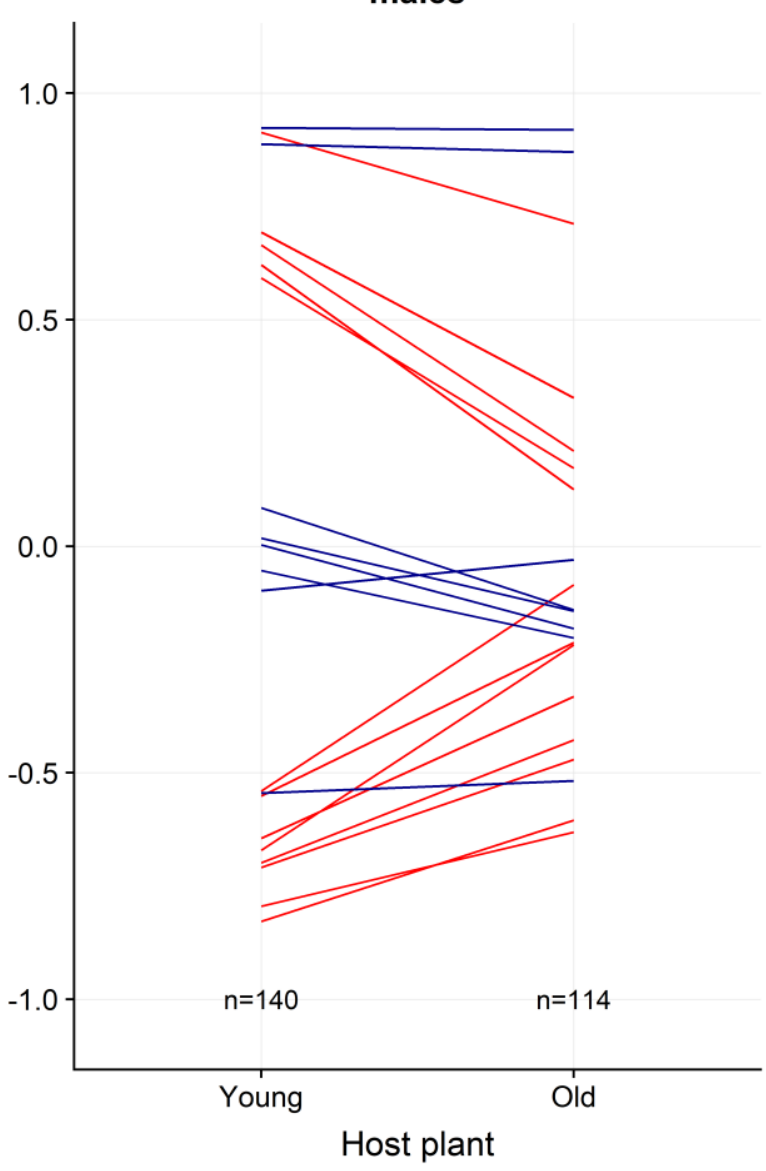

597 Figure 6. Poor host plant quality disrupts phenotypic integration, particularly for males:

598 Correlation coefficients ( $r$ ) between $\log$ transformed trait values for a) females and, b) males 599 on old (poor quality) or young (high quality) host plants. Each line represents the correlation 600 coefficient between one pair of traits. Correlation coefficients that changed significantly $601(\mathrm{P} \leq 0.05)$, due to poor host plant quality, are highlighted in red. Sample sizes for calculating 602 each correlation coefficient are given at the bottom. 